\title{
Assessing the Relationship of Time Management and Academic Performance of the Business Students in Al-Zahra College for Women
}

\author{
Karima Sayari, Revenio Jalagat, Van Dalluay \\ Managerial and Financial Sciences Department, Al-Zahra College for Women, Muscat City, Sultanate of Oman \\ Email address: \\ karima_sayari@yahoo.fr(K. Sayari), revjalagatjr@gmail.com (R. Jalagat), lbvandals_8@yahoo.com (V. Dalluay)
}

To cite this article:

Karima Sayari, Revenio Jalagat, Van Dalluay. Assessing the Relationship of Time Management and Academic Performance of the Business Students in Al-Zahra College for Women. European Business \& Management. Vol. 3, No. 1, 2017, pp. 1-8.

doi: 10.11648/j.ebm.20170301.11

Received: December 11, 2016; Accepted: December 27, 2016; Published: January 16, 2017

\begin{abstract}
Time management is by all means important in all aspects of our lives. Whether in individual capacities or in businesses and organizations, use and management of time is equally important. As applied to educational setting, time is precious to students, teachers, heads and the institution as a whole. These considerations have given the researchers the idea to undertake their study regarding the relationship between time management and students' academic performance. The main objective of this study is to examine the significant relationship between time management variables and students' academic performance. It basically used the descriptive research design in carrying out the study and in selecting the respondents, random sampling were undertaken to 100 students in Managerial and Financial Sciences department of Al-Zahra College for Women with its three specializations: Accounting, Finance, and Business Management departments. Data were analyzed using statistical tools such as frequencies, percentages, weighted mean, standard deviation, regression and correlation. Findings of the study revealed that there is significant correlation of some demographic variables such as age of the respondents and educational degree to students' academic performance. Moreover, time management variable specifically the prioritization significantly correlates to students' academic performance while other variables: procrastination and socialization have no significant relationship to students' academic performance. Based on these findings, it is suggested that, students should observe and undertake prioritization of their tasks and responsibilities to improve their academic performance. Moreover, teachers should also integrate time management concepts and applications in their classes. Trainings and seminars on time management are also encouraged for the students.
\end{abstract}

Keywords: Time Management, Prioritization, Procrastination, Socialization, Students' Academic Performance

\section{Introduction}

Time is precious to anyone. For individuals, time is important in accomplishing individual tasks on time, and in businesses; every single minute can be converted to profitability. According to Macan, et. al. (2000), the secret of achieving success in life is to manage time and resources that everyone possesses equally and paying sufficient attention to planning. This can also be the case on institutions such as schools, colleges and universities. Coming to classes on time and finishing tasks and assignments are very important responsibilities of students to achieve their personal goals and ensure better performance. While various individuals value time differently, offices, colleges and other establishments have set standard time for employees, students and all concerned workers should observe and follow.

Relative to these realities, the main objective of this study is to examine the relationship between time management factors such as prioritization, procrastination, socialization and students' academic performance in Al-Zahra College for Women, Sultanate of Oman. It also investigates the relationship between some demographic variables and the students' academic performance.

\subsection{Statement of the Problem}

Common problems noticed by the researchers especially in the institution where they are presently teaching is that, there 
is absence of prioritization of the students on their school tasks resulting to procrastinations by some of the students especially on delaying examinations due to the lack of time to study. Students were not aware that, procrastination not only waste the teacher's time but also it requires teachers to prepare another exam paper just to accommodate the delays. Also, students usually justify the delays because of the many activities and responsibilities they are doing outside the school like social activities with families and others.

\subsection{Purpose of the Study}

The main purpose of this study is to find out the relationship between time management and students' academic performance using independent variables such as prioritization, procrastination, and socialization. It also examines the level and frequency of the student's involvement with these three variables.

\subsection{Research Questions}

This study tries to address the following questions:

i. What is the demographic profile of the respondents in terms of the following:
a Specialization
b Educational Degree
c Age of Respondents
d School Graduated
e Residential Area
f Accommodation Trend
g Studying Hours

h Tuition Payment Scheme

i Combined Income of Parents

ii. What is the students' responses in terms of their level of prioritization?

iii. What is the students' responses in terms of the frequency of procrastination?

iv. What is the students' responses in terms of their level of socialization?

v. Is there significant relationship between the demographic profile of the respondents and their academic performance?

vi. Is there significant relationship between the time management factors (Prioritization, Procrastination, and Socialization) and the respondents' academic performance?

\subsection{Research Hypothesis}

$\mathrm{H}_{0}$ 1. There is no significant relationship between the demographic factors identified in this study and the students' academic performance.

$\mathrm{H}_{\mathrm{o}}$ 2. There is no significant relationship between time management factors (Prioritization, Procrastination, and Socialization) and the students' academic performance.

\subsection{Conceptual Framework}

The flow of the study can be shown in the diagrammatic format showing the independent variables, the intervening variables and dependent variable as summarized in the figure below.

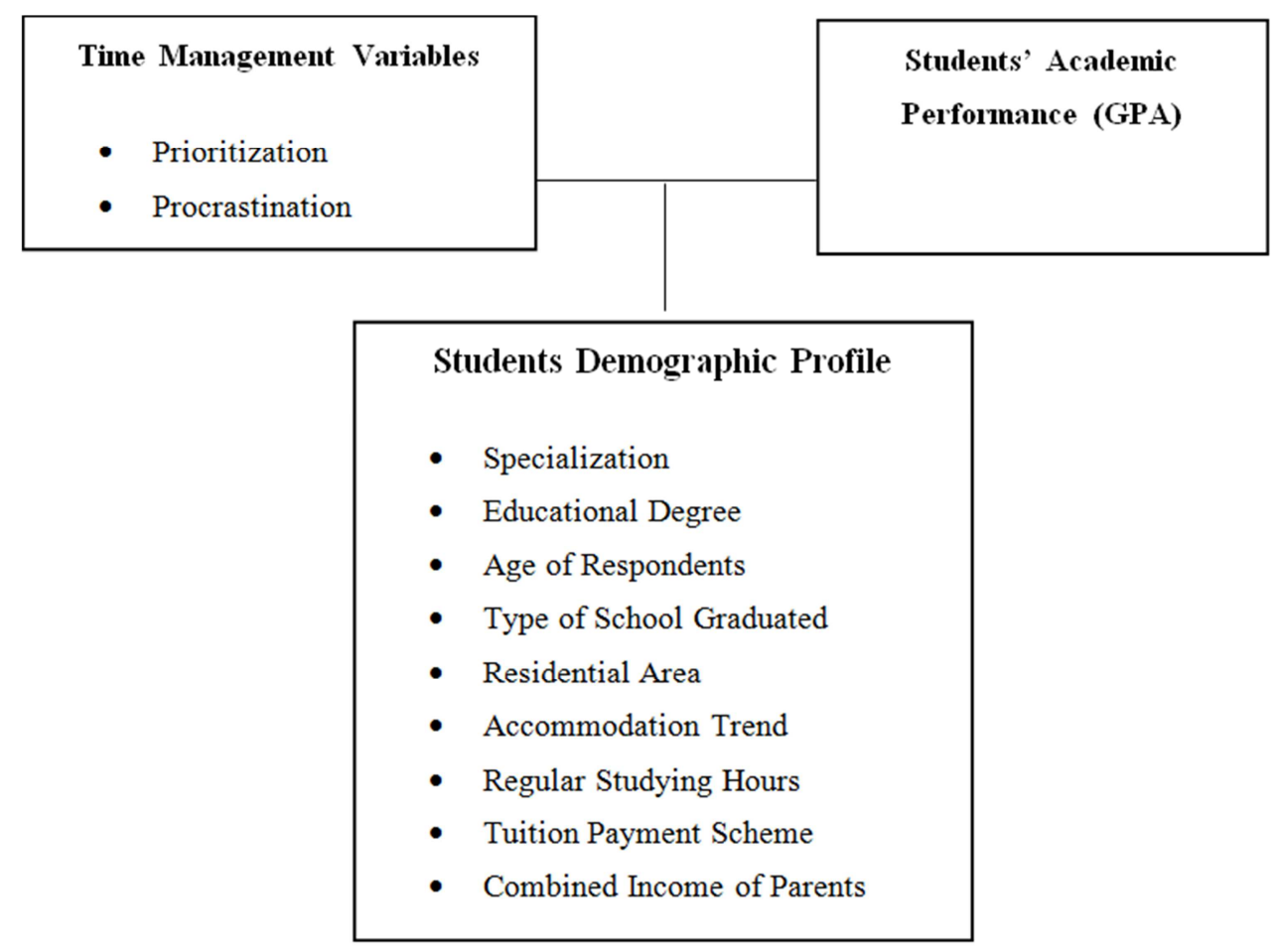

Figure 1. Conceptual Framework.

\section{Literature Review}

The use of time can vary depending on the tasks and responsibilities performed (Alay \& Kocak, 2003). Moreover, the competitive environment nowadays urged the individuals 
and businesses to manage time effectively to achieve desirable outcomes. This section will shed light on the concepts, importance and applications of time management, academic performance, the relationship of time management and performance.

\subsection{Time Management}

Gerald (2002) has defined time management as the art of arranging, organizing, scheduling and budgeting one's time for the purpose of generating more effectiveness in both work and productivity. It is also perceived as set of principles, practices, skills, tools and systems that should work together to achieve and improve the quality of life (Argarwal, 2008; Kelly, 2004). When one is conscious of time then it is imperative that, he sets plans before doing things and sets his priorities in many of his tasks on daily basis. Time management deals with the adequate allocation of time on every activities to be performed in order to effectively manage the tasks and be completed within the time previously set. Prioritizing the works to be done are attributed to how individuals make use of the time effectively by managing the urgency of the needs and the time to be used on each tasks such that time is maximized.

\subsection{Importance of Time Management}

Time management is very important for many reasons. The fact that everyone use time in their daily lives would mean that, time is part of daily life and needed to be managed to end up the day with accomplishment since the passage of time cannot be restored. According to Brigitte, et. al. (2005), time management plays a significant role in improving students' performance and achievements. They added that, every student should possess time management to effectively organize their activities, set goals, and prioritize those activities that requires immediate attention and others. It is also through time management that the students' ability to make decisions can be enhanced thereby using time more effectively (Noftle, Robins \& Richard, 2007). While there is no universally accepted way to manage time, it is still important for individuals like students to value time management and apply it in different contexts.

\subsection{Time Management and Students'Academic Performance}

There are various studies that link time management to students' academic performance. For instance, proper time management positively correlates to better academic performance (Sevari and Kandy, 2011; Adebayo, 2015; Kearns and Gardiner; 2007; Kaushar, 2013). There are several factors that can be considered to demonstrate time management. The study of Nashrullah and and Khan (2015) identified time management variables to include planning (Short-range and long-range), time attitude as independent variables linking to the students' academic performance. Findings showed that time management variables such as short-range, long-range and time attitude are significantly correlated to students' academic achievement. Another study also posits the time management variables to include independent variables such as prioritization, procrastination, socialization and students' academic performance (Adebayo, 2015). Specifically, his study claimed that there is positive relationship between time management factors such as prioritization, procrastination, socialization and the students academic performance. Further implications of the results suggest that students should prioritize their tasks, less procrastination in responding to deadlines and in taking examinations and moderate socialization activities. Karim, et. al, (2015) also links time management factors to include students attitudes and behavior on time and management. Their findings suggest that, both student attitudes and behavior impacts students' academic performance. King (2002) had also emphasized the different external forces that challenges time management and these can be comprised of challenge to one's ability or expertise, which imposes an unwelcome demand on time, abilities and emotional reserves.

Another study conducted by Indreica et al. (2011) examined the influence of effective management to students' academic performance in terms of Grade Point Average (GPA). Findings revealed that, effective management programs elevate the GPA and concluded that successful students are good time managers. Specifically, factors such as time management behaviors, time attitudes and control of time are significant predictors of students' academic performance. Students' academic performance is usually measured on the students' GPA. The latest study conducted by Jalagat (2016) strongly suggests the use of GPA as a measure of student academic performance which also agrees with several studies (Adebayo, 2015; Kaushar, 2013). This study is primarily anchored on Adebayo's utilization of time management variables: Prioritization, Procrastination and Socialization as independent variables to students' academic performance.

\section{Research Methodology}

\subsection{Research Method}

This study utilized the descriptive research design which mainly employed the survey research questionnaires. According to Marsman (1999), descriptive design is a purposive process of gathering, analyzing and tabulating data about prevailing conditions, practices, beliefs, processes, trends and cause and effect relationship and then making adequate and accurate interpretation about such data with the aid of some simple percentile and statistical method.

\subsection{Population and Sampling}

In considering the sample of this study, the researchers employed the random sampling for the total population of 450 students from the Managerial and Financial Sciences Department of Al-Zahra College for Women, Sultanate of Oman. Al-Zahra College for Women is one of the colleges and universities in the Sultanate of Oman and operates under the direct supervision of the Ministry of Higher Education. 
The sample taken reached 100 respondents of which 75 students are business management majors, 15 finance majors, and 10 accounting majors.

\subsection{Research Instruments}

This study primarily used the structured questionnaires to gather the information. The self-made questionnaire is divided into two sections. The first section contains the demographic profile of the respondents and the second section shows the questions pertaining to the time management factors: prioritization, procrastination, and socialization using the 5-point Likert Scale.

\subsection{Data Gathering Procedure}

The data were gathered with the consent of the Department Head of Managerial and Financial Sciences Department whom the researchers are staffs members. The questionnaires were then distributed to the 100 respondents and the responses were all retrieved within one week. Because of the accessibility of the information, retrieval of the data were done as desired.

\subsection{Data Analysis}

In this study, the data were analyzed quantitatively with the use of statistical tools. The first section which contains the demographic profile were analyzed using frequencies and percentages. The second section consisting of time management factors were analyzed using the weighted mean and standard deviation. It was further analyzed with the use of correlation and regression to establish the relationship between time management variables and students' academic performance. Specifically, the Pearson Correlation Coefficient was used to determine the relationship between the students' demographic profile consisting of Specialization; Educational Degree; Age; Type of School Graduated; Residential Area; Accommodation Trend; Regular Studying Hours; Tuition Payment Scheme; Combined Income of Parents and their academic performance while the regression analysis was applied in determining the relationship between the time management variables such as prioritization, procrastination, socialization and the students' academic performance. The correlation and regression were both tested at 0.05 level of significance.

\subsection{Reliability and Validity of the Instrument}

The instruments used in this study was examined and assessed for its face and content validity. The face validity is endeavored through examining thoroughly the layout and structure of the instrument while validity is achieved through testing and re-testing the instruments used to ensure reliability of the instruments used.

\section{Findings and Discussions}

This section presents the results from the statistical interpretation of the study based on the research questions.
Table 1. Demographic Profile of the respondents.

\begin{tabular}{|c|c|c|}
\hline Specialization & f & $\%$ \\
\hline Accounting & 10 & 42.00 \\
\hline Business Management & 75 & 53.00 \\
\hline Finance & 15 & 5.00 \\
\hline TOTAL & 100 & 100.00 \\
\hline Educational Degree & $\mathrm{f}$ & $\%$ \\
\hline Diploma & 5 & 5.00 \\
\hline Certificate/Bachelors & 95 & 95.00 \\
\hline TOTAL & 100 & 100.00 \\
\hline Age of Respondents & $\mathrm{f}$ & $\%$ \\
\hline $17-22$ & 54 & 54.00 \\
\hline $23-28$ & 42 & 42.00 \\
\hline $29-34$ & 1 & 1.00 \\
\hline 35 and above & 3 & 3.00 \\
\hline TOTAL & 100 & 100.00 \\
\hline Type of School Graduated & $\mathrm{f}$ & $\%$ \\
\hline Government & 98 & 98.00 \\
\hline Private & 2 & 2.00 \\
\hline TOTAL & 100 & 100.00 \\
\hline Residential Area & $\mathrm{f}$ & $\%$ \\
\hline Urban & 44 & 44.00 \\
\hline Rural & 56 & 56.00 \\
\hline TOTAL & 100 & 100.00 \\
\hline Accommodation Trend & $\mathrm{f}$ & $\%$ \\
\hline Hostel & 52 & 52.00 \\
\hline Own House/Residence & 48 & 48.00 \\
\hline TOTAL & 100 & 100.00 \\
\hline Regular Studying Hours & $\mathrm{f}$ & $\%$ \\
\hline Less than 1 hour & 6 & 6.00 \\
\hline $1<2$ hours & 15 & 15.00 \\
\hline 2 - 3 hours & 43 & 43.00 \\
\hline $4-5$ hours & 25 & 25.00 \\
\hline More than 5 hours & 11 & 11.00 \\
\hline TOTAL & 100 & 100.00 \\
\hline Tuition Payment Scheme & $\mathrm{f}$ & $\%$ \\
\hline Government Paid & 83 & 83.00 \\
\hline Self-Support & 17 & 17.00 \\
\hline TOTAL & 100 & 100.00 \\
\hline Income of Parents & f & $\%$ \\
\hline $0-499$ & 34 & 34.00 \\
\hline $500-999$ & 44 & 44.00 \\
\hline $1000-4999$ & 14 & 14.00 \\
\hline $1500-1999$ & 6 & 6.00 \\
\hline 2000 and above & 2 & 2.00 \\
\hline TOTAL & 100 & 100.00 \\
\hline GPA & $\mathrm{f}$ & $\%$ \\
\hline Fail (0-49) & & 0 \\
\hline Poor (50-59) & & 3 \\
\hline Fair (60-69) & & 27 \\
\hline Good (70-79) & & 46 \\
\hline Very Good (80-89) & & 19 \\
\hline Excellent $(90-100)$ & & 5 \\
\hline TOTAL & 100 & 100.00 \\
\hline
\end{tabular}

The table 1 displays the demographic profile of the respondents. Highlights from the results depict that, out of $100(\mathrm{~N}=100)$ respondents, 75 samples or $75 \%$ of them are business management students and the rest are both finance and accounting students. About $95 \%$ of the respondents prefer bachelor's degree over diploma as educational degree. Most of the students with $50 \%$ are aged 17-22 followed by $42 \%$ aged 23-28, the rest are shared between ages $29-34$ and above. In knowing the type of school graduated, $98 \%$ are graduates from Government schools where $56 \%$ of them are living in rural residential area. About $52 \%$ are living in the 
hostel while the $42 \%$ live in their own houses. Studying hours showed that $43 \%$ of the students regularly can study in 2-3 hours followed by $25 \%$ for those students who can spent 4-5 hours studying while the least or $6 \%$ spent regular studies in less than an hour. Moreover, $83 \%$ of the respondents or 83 out 100 are government paid which means that the government pay their tuition and charges. Most of the respondents or $44 \%$ had their combined parent's income between 500-999 OMR per month. Lastly, with regards to the students GPA, $46 \%$ or 46 out of 100 respondents achieve good grades (70-79); 27\% attained fair marks (60-69); 19\% awarded very good GPA (80-89) while 5\% are exceptionally excellent (90-100). These findings show the distribution of respondents according to their profile.

Table 2. Students' responses on their level of prioritization.

\begin{tabular}{|c|c|c|}
\hline Prioritization & Weighted Mean & SD \\
\hline 1. I plan out my daily duties with the right strategy & 3.01 & 1.05 \\
\hline 2. I prepare a list of my tasks to be performed in sequential order. & 3.07 & 1.02 \\
\hline 3. I see to it that I prioritize the task according to what should be the first to be done. & 3.31 & 0.98 \\
\hline 4. I set enough time for my daily duties activities. & 3.39 & 0.97 \\
\hline 5. I check the accomplishments of my tasks based on the priorities made. & 3.28 & 1.12 \\
\hline 6. I monitor my daily activities by comparing my plan against what has been actually done and reconcile any differences. & 3.27 & 1.04 \\
\hline Average & 3.22 & \\
\hline
\end{tabular}

Numerical Scale: 1=Not a Priority (1-1.99); 2=Low Priority (2-2.99); 3=Neutral (3-3.99); 4=High Priority (4-4.99); 5=Very High Priority (5-5.99)

Table 2 presents the students' level of prioritization of their tasks and responsibilities. Generally, the findings reveal that the level of prioritization is regarded as "Neutral" with average weighted mean of 3.22. This might imply that the students' perception of prioritization is neither advantageous nor disadvantageous to them. Furthermore, the results also indicate the lack of skills and abilities of the students to prioritize their tasks and responsibilities as evidenced from the results in questions 1 to 6 .

Table 3. Students' responses on their frequency of procrastination.

\begin{tabular}{ll}
\hline Procrastination & Weighted Mean \\
\hline 7. I always say that there is always enough time to finish my tasks. & 2.87 \\
8. I cancel my tasks without valid reasons. & 2.68 \\
9. I am not in hurry to finish my scheduled tasks. & 2.61 \\
10. I always asks extension of my assignment submission. & 3.00 \\
11. I love playing computer games even it delays in task compliance. & 2.38 \\
12. I ignore deadlines and have submitted assignments on time. & 2.56 \\
13. I study my lessons normally few days before examination. & 2.73 \\
14. I don't mind to be late as long as I will be there during classes. & 2.45 \\
Average & 1.00 \\
\hline
\end{tabular}

Numerical Scale: $1=$ Never (1-1.99); 2=Rarely (2-2.99); 3=Sometimes (3-3.99); 4=Often (4-4.99); 5=Very Often (5-5.99)

Table 3 reflects the frequency of procrastination that the respondents committed with the duration of their study. On the average, procrastination is rarely done by the respondents with weighted mean scores of 2.65 . When ask on question 7 , the results show that the frequency of procrastination is rarely committed with 2.87 weighted mean scores. However, question 10 shows the students' frequency of asking extension of assignment submission with a weighted mean of 3.00 remarked as "Sometimes" committed. Question 13 is also observable with 2.73 weighted mean scores that students normally study lessons just few days before the examination.

Table 4. Students' responses on their level of socialization.

\begin{tabular}{ll}
\hline Socialization & Weighted Mean \\
\hline 15. I spend more time texting and chatting with friends. & 2.58 \\
16. I do browsing and chatting in Facebook, twitter, etc. & 2.40 \\
17. I go parties with my friends. & 2.50 \\
18. I spend more time in networking and meeting new friends. & 2.51 \\
19. I get involved in physical activities in gym and other exercises. & 2.59 \\
20. I am actively involved on weekend activities with my family. & 3.00 \\
21. I regularly get involved with religious activities. & 1.19 \\
22. I am spending more time on shopping malls and hypermarkets. & 1.12 \\
23. I watch movies in Cinemas and Theaters. & 0.93 \\
24. I spend time in playhouses located in shopping malls and others. & 1.11 \\
Average & 0.94 \\
\hline
\end{tabular}

Numerical Scale: $1=$ Never (1-1.99); 2=Rarely (2-2.99); 3=Sometimes (3-3.99); 4=Often (4-4.99); 5=Very Often (5-5.99)

Table 4 depicts the frequency of socialization by the respondents within the duration of their study. Average result reveals that, majority of the respondents "Rarely" give time for socialization activities with weighted mean scores of 2.56. 
This result can be supported by observations that, majority of the respondents reside outside the capital region of Muscat City where the exposure of social activities are not visible. Highlights from the results specifically show that, most of the students' socialization activities are involved on weekend family activities with the weighted mean scores of 3.00 "Sometimes" while the rest of the responses are marked as "Rarely" done. It is also interesting to note that, question 22 displays an observable findings that students also spend more time on shopping to malls with weighted mean scores of 2.84 .

Table 5. Correlation between the respondents' demographic profile and their academic performance.

\begin{tabular}{llll}
\hline Factors & Coefficient & Probability \\
\hline Specialization & -2.922 & 0.112 & Significance \\
Educational Degree & 13.269 & $0.009^{*}$ & $\mathrm{NS}$ \\
Age of Respondents & 0.6312 & $0.011^{*}$ & $\mathrm{~S}$ \\
School Graduated & 10.196 & 0.113 & $\mathrm{~S}$ \\
Residential Area & -1.286 & 0.489 & $\mathrm{NS}$ \\
Accommodation Trend & 2.028 & 0.299 & $\mathrm{NS}$ \\
Regular Studying Hours & 0.540 & 0.565 & $\mathrm{NS}$ \\
Tuition Payment Scheme & -3.861 & 0.182 & $\mathrm{NS}$ \\
Combined Income of Parents & 0.489 & 0.613 \\
\hline
\end{tabular}

S-Significant NS-Not Significant *Correlation is significant at the 0.05 level (2-tailed)

The findings clearly show that, when applying the correlation to determine the relationship between demographic profiles and the students' academic performance, only the two independent variables namely educational degree and age of respondents have significant relationship with their p-values of 0.009 and 0.011 respectively which are less than 0.05 level of significance. This can be interpreted that as the educational degree increases, the performance will also increase and while age of the respondents increase, the students' academic performance will also increase. Interestingly, the studying hours which are used to be a predictor of students' academic performance is found to have no relationship to academic performance that can also be interpreted that, regardless of whether you spent short or long time with your studies, the results might be the same. Also, specialization has nothing to do with students' academic performance. Therefore, the hypothesis is rejected.

Table 6. Regression Analysis.

\begin{tabular}{|c|c|c|c|c|c|}
\hline Statistics Summary (Multiple R) & R Square & Adjusted R Square & Std. Error of Estimate & & \\
\hline 0.676 & 0.456 & 0.439 & 6.527 & & \\
\hline ANOVA & Sum of Squares & df & Mean Square & $\mathrm{F}$ & Sig. \\
\hline Regression & 3435.238 & 3 & 1145.079 & & \\
\hline Residual & 4089.512 & 96 & 42.599 & 26.880 & 0.000 \\
\hline Total & 7524.75 & 99 & & & \\
\hline & Unstandardized Coefficient (B) & Std. Error & Standardized Coefficient (Beta) & $\mathrm{T}$ & Sig. \\
\hline (Constant) & 56.154 & 2.281 & & 24.615 & 0.000 \\
\hline PROCRASTINATION & 0.136 & 1.988 & -3.810 & 0.068 & 0.946 \\
\hline SOCIALIZATION & -0.922 & 2.138 & -5.236 & -0.464 & 0.643 \\
\hline
\end{tabular}

Predictors: (Constant):Prioritization, Procrastination, Socialization

Dependent Variable: Students' Academic Performance

The table shows the results of regression analysis between the independent and the dependent variables. The results from R Square of $45.6 \%$ explains the variability of the dependent variable, the students' academic performance to the independent variables namely: prioritization, procrastination and socialization. Therefore, about $54.4 \%$ of the variation cannot be explained by the independent variables. It also clearly depicts that, only prioritization with $(\mathrm{p}=0.000<0.05)$ has significant relationship on students' academic performance tested at 0.05 level of significance. Both procrastination and socialization have no impact on students' academic performance with 0.946 and 0.643 respectively where the statistical results are more than 0.05 level of significance. This can be interpreted that, when students prioritize their tasks and responsibilities, they can achieve their objectives and perform better in their studies. On the other hand, low prioritization significantly result to low academic performance. This result is consistent with various studies that time management particularly prioritization positively affects students' academic performance (Sevari and Kandy, 2011; Adebayo, 2015; Kearns and Gardiner; 2007; Kaushar, 2013). However; the procrastination and socialization results imply that, whether the students delay their tasks or not, it will not affect their academic performance and regardless of whether they spend more time on social activities or not, there is no effect on their academic performance. These results contradicts the findings of Adebayo (2015) stating that both procrastination and socialization correlates to students' academic performance.

\section{Summary of Findings}

This study has examined the relationship between time 
management variables such as prioritization, procrastination, and socialization on the students' academic performance. It has also identified the demographic factors that correlated to students' academic performance. The findings revealed that, out of the demographic variables identified in this study, only educational degree and age of the respondents with $(0.009<.05)$ and $(0.011<0.05)$ respectively significantly correlates to students' academic performance which can be interpreted that students from different educational degree and ages varies in their usage of time. This can further be interpreted that as the degree is going higher and the age also increase, their time management also improve causing the increase in academic performance. All other variables therefore do not have relationship to the students' academic performance. With regard to the time management variables, findings show that, prioritization has significant relationship to students' academic performance while two other variables: procrastination and socialization have no significant relationship with students' academic performance. These findings agree with the previous studies claiming that, time management positively correlates to students' academic performance (Sevari and Kandy, 2011; Adebayo, 2015; Kearns and Gardiner; 2007; Kaushar, 2013). However; specifically the findings on the relationship between procrastination and socialization and the students' academic performance contradicts to the study of Abedayo (2015) where his findings show that both procrastination and socialization significantly correlates to students' academic performance. This can be because, there are different levels of procrastinations and in the case of Al-Zahra, most responses remarked as "Rarely" on the frequency and level of procrastinations committed by students.

\section{Conclusion}

Based on these findings, it can be concluded that time management has significant relationship on students' academic performance. Some demographic variables also significantly correlates to students' academic performance which in this study include educational degree and age of the respondents being proven to be significantly correlated. Specifically, prioritization should be given due consideration by students because it proved to be a significant predictor of students' better academic performance. Results from hypothetical assumptions prove that, when the level of prioritizing is high it also connotes higher students' academic performance. Although procrastination and socialization have no significant relationship in this study, it does not mean that it can be ignored because previous studies affirmed its relationship hence; it cannot be underestimated.

\section{Recommendations}

Based on the findings of this study, the following recommendations were made:

Students should take into consideration the importance and value of prioritizing to ensure accomplishment of their tasks and activities and more importantly to improve their academic performance. Teachers are also encouraged to integrate the importance and application of time management to classes especially to management subjects where the concept of planning and management are mostly tackled and to minimize the incidents of procrastination. Although procrastination has no significant impact on students' academic performance, efforts should also be considered to lessen if not eliminate the cases of procrastinations because it delays the accomplishment of tasks and responsibilities of both the students and the teachers. It would also be beneficial for students if trainings and seminars related to time management can be done.

However; these findings limit only to the chosen organization, Al-Zahra College for Women which would mean that when applied to different settings, varied results can be derived. It is therefore recommended that an extensive study should be done to further come up with justifiable outcomes.

\section{References}

[1] Adebayo, F. (2015). Time Management and Students' Academic Performance in Higher Institution, Nigeria: A Case Study of Ekiti State. International Research in Education, 3 (2): p. 1-11.

[2] Agarwal, A. (2008). Self-discipline for student-influences on time management. Retrieved November 25, 2012 from, $\mathrm{http}: / /$ www.ezinarticles.com.

[3] Alay, S., \& Koçak, S. (2003). Relationship between time management and academic achievement of university students. Kuram ve Uygulamada Eğitim Yönetimi Dergisi, 35, 326-335.

[4] Brigitte, J. C., Claessens, Eerde, W. V., Rutte, C. G, Roe, R. A. (2005). A review of the Time management literature. Emerald Group Publishing Limited, 36 (2).

[5] Gerard, M. (2002). Negative influences of time management. Retrieved November 22, 2016 from, http:// www.eskishore. Com/tiometips52.asp.

[6] Jalagat, R. (2016). Performance in CPA Examination: Benchmarking for Opportunities to Meet Market Demands. International Journal of Social Science and Economic Research (IJSSER), 1 (9): p. 1350-1381.

[7] Indreica, E. S., Cazan, A. M., \&Truța C. (2011). Effects of learning styles and time management on academic achievement. Procedia - Social and Behavioral Sciences, 30 (1): p.1096-1102.

[8] Karim., \& Mitra, K. (2015), Time management skills impact on self-efficacy and academic performance. Journal of American Science, 7 (12).

[9] Kaushar, M. (2013). Study of Impact of Time Management on Academic Performance of College Students. Journal of Business and Management, 9 (6): p. 59-60.

[10] Kearns, H., and Gardiner, M. (2007). Retrieved November 25, 2016 from, http://web.ebscohost.com/. 
[11] Kelly, M. (2004). Get time on your side, Careers \& Universities, 24 (4): p. 27-28.

[12] King, J. M. C. (2002). The procrastination syndrome, signs, symptoms, and treatment cultural studies and analysis. Philadelphia: Stoke Publisher.

[13] Macan, T. H., Shahani, C., Dipboye, R., \& Phillips, A. P. (1990). College students' time management: Correlations with Academic performance and stress. Journal of Educational Psychology, 82 (4): p.760-780.
[14] Marsman, K. (1999). Computing for Social Research: Practical Approaches: Belmont, CA. Wadsworth Publishing.

[15] Noftle, E., Robins., \& Richard, W. (2007). Personality predictors of academic outcomes: Big five correlates of GPA \& SAT scores. Journal of Personality and Social Psychology, 93: 116-130.

[16] Sevari, K., \& Kandy, M. (2011). Time management skills impact on self-efficacy and academic performance. Journal of American Science, 7 (12): p. 720-726. 